\title{
Influence of temperature on muscle fibre hyperplasia and hypertrophy in larvae of blackspot seabream, Pagellus bogaraveo
}

\author{
Paula Silva $^{1,2}$, Luísa Maria Pinheiro Valente ${ }^{1,2}$, Mercedes Olmedo ${ }^{3}$, Blanca Álvarez-Blázquez ${ }^{3}$, \\ Maria Helena Galante ${ }^{1}$, Rogério Alves Ferreira Monteiro ${ }^{1,2}$ \& Eduardo Rocha ${ }^{1,2}$ \\ ${ }^{1}$ ICBAS - Institute of Biomedical Sciences Abel Salazar, UPorto - University of Porto, Porto, Portugal \\ ${ }^{2}$ CIMAR/CIIMAR - Interdisciplinary Centre for Marine and Environmental Research, UPorto - University of Porto, Porto, \\ Portugal \\ ${ }^{3}$ Instituto Español de Oceanografia, Cabo Estay, Vigo, Spain
}

Correspondence: E Rocha, Laboratory of Histology and Embryology, ICBAS - Institute of Biomedical Sciences Abel Salazar, Lg. Prof. Abel Salazar 2, 4099-003 Porto, Portugal. E-mail: erocha@ icbas.up.pt

\begin{abstract}
The effects of temperature on Pagellus bogaraveo muscle cellularity were investigated, by morphometry, throughout the endogenous feeding stage, testing two rearing temperatures: 14 and $18^{\circ} \mathrm{C}$. The following parameters were estimated in transversal body sections at post-opercular and post-anal body levels: the total cross-sectional muscle area, the total number of fibres and the mean cross-sectional fibre area. At hatching, no significant influence of the temperature was observed on the morphometric parameters measured in the white muscle. At mouth opening, an increase in the number of post-opercular white fibres was promoted by the highest temperature. During embryonic development, the red muscle fibre number in the post-anal part of the larvae increased with higher temperature, but it appears that the difference was no longer present at mouth opening. An increase in the fibre area and in the total cross-sectional area of red muscle at the post-anal level was promoted by a $4{ }^{\circ} \mathrm{C}$ increase in the temperature during the vitelline phase. In conclusion, the axial musculature of blackspot seabream embryos/larvae reacted differently to temperature influence according to the body location, strongly supporting the need to look at and account for different body locations when evaluating muscle cellularity in fish, namely in growth/aquaculture-related studies.
\end{abstract}

Keywords: temperature, Pagellus bogaraveo, fish larvae, muscle growth, blackspot seabream

\section{Introduction}

Several studies suggested that rearing temperature can influence muscle cellularity at hatching and/or in the subsequent stages of fish, but these effects vary widely among and within fish species. Generally, studies have taken eggs from individual or mixed families, incubated them at different temperatures and sampled the offspring at defined life-history stages (e.g. hatching or first feeding). Various patterns of response of muscle cellularity to temperature have been described at hatch and at the start of exogenous feeding. In recently hatched larvae of herring (Clupea harengus, Linnaeus), higher temperatures increased white muscle fibre hyperplasia (Vieira \& Johnston 1992; Johnston, Vieira \& Abercromby 1995). Nevertheless, in a different study with herring (Johnston 1993) and in salmon (Salmo salar, Linnaeus) (Usher, Stickland \& Thorpe 1994; Nathanailides, López-Albors \& Stickland 1995), hypertrophy of the white muscle fibres was induced by an increase in the rearing temperature. In sea bass (Dicentrarchus labrax, Linnaeus), the slight increase in the water temperature during incubation had a positive effect on both hypertrophic and hyperplastic muscle growth, from the beginning of the exogenous feeding onwards (Ayala, López-Albors, Gil, Latorre, Vásquez, GarcíaAlcázar, Abellán, Ramírez \& Moreno 2000). Another study, with the same species, showed that when the temperature increase was maintained until mouth opening [5-6 days post-hatching (dph)], the larval and early larval muscle growth was improved, and 
that the histochemical maturity of white muscle was advanced in prewarmed specimens (López-Albors, Ayala, Gil, García-Alcázar, Abellán, Latorre, Ramírez-Zarzosa \& Vázquez 2003). This inter- and intraspecific variability in the response to temperature may reflect genetic variation, abiotic factor effects and/or could be related to distinct body sampling sites, as some of those studies were carried out in anterior positions of the larvae trunk (Vieira \& Johnston 1992; Johnston 1993; Johnston et al. 1995) and others in posterior ones (Nathanailides et al. 1995; Ayala et al. 2000; López-Albors et al. 2003). In gilthead sea bream larvae (Sparus aurata, Linnaeus) of 20 days, Rowlerson, Mascarello, Radaelli and Veggetti (1995) found significant differences between the muscle fibre size distributions at the anal opening level and at a level found $2 \mathrm{~mm}$ more caudally. In Atlantic salmon, different muscle fibre size distributions were also observed among three longitudinal sampling points (Johnston 2001). To the best of our knowledge, previous works were not particularly focused on comparing the effects of temperature on muscle cellularity between the distant zones of the trunk musculature that display different gross morphology.

The blackspot seabream (Pagellus bogaraveo, Brunnich) is common along the Southern European Atlantic continental shelf and throughout the Mediterranean, and its intensive production has increased in the last decade. In the natural environment, blackspot seabream spawning occurs at the end of winter between January and April (Bauchot \& Hureau 1990) and the peak spawning activity is reached between February and May (Sánchez 1983; Krug 1990). In captivity, spawning coincides more or less with these periods, being at a controlled temperature of $14{ }^{\circ} \mathrm{C}$ from February through to May at north-west of the Iberian Peninsula (Olmedo, Peleteiro, Alvarez-Blázquez \& Gómez 1998). The present work was carried out to investigate the influence of two different water temperatures (14 and $18^{\circ} \mathrm{C}$ ), used in incubating early embryos and sustaining the vitelline phase, on the blackspot seabream axial muscle cellularity at two time points: at hatching and at mouth opening. Another question we wanted to address concerned the hypothesis that the effect of temperature on muscle growth is different along a 'rostro-caudal'gradient.

\section{Materials and methods}

\section{Fish}

The experiment was carried out at the Instituto Español de Oceanografía (IEO) (Centro Oceanográfico de
Vigo, Spain), using eggs obtained from an adult stock of blackspot seabream (68 reproducers) maintained in a flow-through seawater system at natural seawater temperature $\left(14^{\circ} \mathrm{C}\right)$. Eggs were obtained at the end of March of 2006, and were divided into two tanks (ca. 6390 eggs for each tank): one tank was maintained at $14 \pm 0.1^{\circ} \mathrm{C}$ and another was reared at $18.0 \pm 0.1{ }^{\circ} \mathrm{C}$ from fertilization to mouth opening. Egg incubation and rearing were carried out in cylindroconical tanks $(150 \mathrm{~L})$ and exposed to continuous light (1500-2000 lx).Water quality variables (i.e. temperature, oxygen level, $\mathrm{pH}$, ammonia, nitrite and nitrate) were checked daily. The oxygen level was $99 \%$ saturation $(8.1 \pm 0.1 \mathrm{ppm}$ in both tanks). The rate of water flow, recirculation, $\mathrm{pH}\left(8.2 \pm 0.1\right.$ in the $14{ }^{\circ} \mathrm{C}$ tank and $8.1 \pm 0.1$ in the $18^{\circ} \mathrm{C}$ tank, with no significant differences between tanks) and ad libitum supply of live plankton and commercial fish food of appropriate particle sizes were held constant (all according to the standard procedures of the IEO fish breeding laboratory). Nitrite and nitrate were barely detectable in all the tanks (i.e. $<0.05 \mathrm{ppm}$ ).

The growth performance was described using the following parameters:

$$
\begin{aligned}
& \text { Thermal-unit growth coefficient }(\mathrm{TGC}) \\
& \quad=100 \times\left[\left(\mathrm{FBW}^{1 / 3}-\mathrm{IBW}^{1 / 3}\right) / \Sigma(\mathrm{T} \times \text { Days })\right] \\
& \text { Specific growth rate }(\mathrm{SGR}) \\
& \quad=100 \times((\mathrm{LnFBW}-\mathrm{LnIBW}) / \text { Days }) \\
& \text { Condition factor }(\mathrm{K}) \\
& \quad=\mathrm{FBW} / \text { Length }^{3} \times 100
\end{aligned}
$$

where IBW is the mean initial body weight (mg) (at hatching), FBW is the mean final body weight (mg) (at mouth opening) and $\mathrm{T}$ is the water temperature $\left({ }^{\circ} \mathrm{C}\right)$.

\section{Sample preparation}

Larvae sampled at hatching (Day 0 of the experiment was defined as the time when $50 \%$ of the eggs had hatched) and at mouth opening (MO) were killed by providing excess anaesthesia in a solution of MS-222 (Sigma-Aldrich, St Louis, MO, USA), fixed in $4 \%$ paraformaldehyde in phosphate buffer. Larvae were later paper dried and bulk-weighed (a total of six groups each with six larvae per treatment) using a digital balance (accuracy $0.001 \mathrm{~g}$ ). Thereafter, the total length was individually measured under a microscope with a graduated eyepiece to estimate growth. For morphometric analysis, six larvae per group and per sampling level (i.e. 24 larvae in total) were routinely dehydrated in a graded ethanol series, cleared in 
xylol and, finally, embedded in paraffin. The entire larva body was transversely sectioned $(7 \mu \mathrm{m})$ and all the sections were saved. Every 10th section was then sampled, stained with haematoxylin-eosin before being coversliped and analysed under the microscope to select the two body sections of individual fish, at both post-opercular and post-anal locations chosen to measure the morphometric parameters. As our primary goal was to perform comparisons between the two experimental groups, the same laboratory protocol was used for preparing tissue samples (all animals being processed at the same time), to minimize the shrinkage problem.

\section{Morphometry}

Morphometric variables were measured in transversal body sections of individual fish, at both post-opercular and post-anal locations, to estimate the total crosssectional muscle area [ $A$ (muscle)], the total number of fibres [ $N$ (fibres)] and the mean cross-sectional fibre area $[\bar{a}$ (muscle fibre)], of the fast white muscle (innermost fibres) and for slow red muscle (outermost fibres).

The study was performed using an interactive image analysis system (CAST-Grid; Olympus Denmark A/S, Ballerup, Denmark; version 1.6), working with a live-image captured using a CCD-video camera (Sony, Tokyo, Japan). The light microscope (BX50; Olympus, Tokyo, Japan) used was equipped with a fully motorized stage (Prior Scientific, Rockland, MA, USA), thus allowing meander sampling with an ( $x-y$ axis) accuracy of $1 \mu \mathrm{m}$. The cross-sectional (half) white muscle area $[A$ (white muscle)] was automatically computed using the software after the physical limits of interest in the section were traced by the operator. Precise tracing was made on the monitor, at a magnification of $\times 1608$, using live-image primarily captured under a $\times 40$ objective lens. Because it had been confirmed that no significant differences existed between the right and the left side of the fish, an estimate of the total cross-sectional area [ $A$ (white muscle)] was performed by doubling the computed value.

\section{Red muscle}

The cross-sectional red muscle area [ $A$ (red muscle)] was estimated as follows:

$A($ red muscle $)=\bar{a}($ red muscle fibre $) \times N($ red fibres $)$

where $\bar{a}$ (red muscle fibre) is the mean individual red muscle fibre cross-sectional area and $N$ (red fibres) is the total number of red muscle fibres per cross-section.

The mean individual red muscle fibre cross-sectional area $[\bar{a}($ red muscle fibre) $]$ of larvae was estimated using the 2D-nucleator technique. The area of any object irrespective of its size, shape and orientation is rapidly and unbiasedly estimated using that technique by measuring the distance between a 'central point' (a virtual one) within the object and the intersections between the object boundary and radiating test lines (four in our case) (Larsen, Gundersen \& Nielsen 1998; Savnik, Bliddal, Nyengaard \& Thomsen 2002). The mathematical formula underlying this technique reads as follows:

$$
\bar{a}(\text { red muscle fibre })=\pi \bar{I}^{2}
$$

where $I$ is the distance from the 'central point' to the object boundary measured in a pre-determined number of random directions. For our case, the central point' was chosen by the operator as the virtual most approximate centre of a cross-sectioned fibre. All the procedures and measurements were performed using the Grid software (CAST-GRID). All fibres in a body cross-section were measured, also at a final magnification of $\times 1608(\times 40$ objective lens $)$.

\section{White muscle}

For the sake of measuring efficiency (high speed/effort ratio), the mean individual white muscle fibre cross-sectional area $[\bar{a}$ (white muscle fibre) $]$ was indirectly estimated by unbiasilly combining $A$ (white muscle) and $N$ (white fibres), as follows:

$$
\begin{array}{r}
\bar{a}(\text { white muscle fibre })=A(\text { white muscle }) \\
/ N(\text { white fibres })
\end{array}
$$

As with red muscle, the total number of white fibres [ $N$ (white fibres)] was obtained by counting all the fibres that appeared in sections.

\section{Hypertrophy and hyperplasia}

The relative contribution of hypertrophy and hyperplasia towards the increase in the cross-sectional area was estimated as applied previously (Valente, Rocha, Gomes, Silva, Oliveira, Monteiro \& Fauconneau 1999):

$$
\Delta A\left(\mu \mathrm{m}^{2}\right)=N_{\mathrm{m}} \Delta \bar{a}\left(\mu \mathrm{m}^{2}\right)+\bar{a}_{\mathrm{m}}\left(\mu \mathrm{m}^{2}\right) \Delta N
$$

where $\Delta$ is calculated between two sampling times ( $t$ and $t+1$ ) and $N_{\mathrm{m}}$ and $\bar{a}_{\mathrm{m}}$ refer to the mean total number of fibres and fibre area at $t$. 


\section{Statistics}

Data were analysed using the software STATISTICA (version 6; StatSoft,Tulsa, OK, USA). For all statistical tests, the significance level was set at $\alpha=0.05$. The analysis was carried out using the Mann-Whitney Unon-parametric test in order to determine the influence of water temperatures on larvae growth. Because fish reared at different temperatures do not necessarily hatch or start feeding at the same developmental stage, the effects of the temperature on the morphometric parameters were analysed for covariance (ANCOVA), in which temperature was set as the independent variable while the total length was set as a covariate. In the specific cases, where the ANCOVA assumptions failed, data transformations (inverse value) were performed to meet the assumptions. When differences were significant, individual means were compared using the Tukey's honest significant difference test. Such pair comparisons were also tested using the Mann-Whitney U-test, which showed the same significant differences; the $P$-values given are from Tukey's test. For a particular age and temperature, comparisons between post-opercular and postanal morphometric values were performed using the Student's $t$-test for paired samples, after checking normality and homogeneity of variance, using the Kolmogorov-Smirnoff and the Levene tests respectively (Zar 1996).

\section{Results}

\section{Larvae development and growth performance}

Blackspot seabream embryos developed faster at higher temperatures. Embryonic life (from fertilization to hatching) lasted $72 \mathrm{~h}$ at $18{ }^{\circ} \mathrm{C}$ and $96 \mathrm{~h}$ at $14^{\circ} \mathrm{C}$. Pre-larval (hatching - mouth opening) development was also accelerated by a higher cultivation temperature (occurred at $6 \mathrm{dph}$ at $18{ }^{\circ} \mathrm{C}$ versus $9 \mathrm{dph}$ at $14{ }^{\circ} \mathrm{C}$ ). Data on growth are reported in Table 1 . The body weight of larvae reared at $18{ }^{\circ} \mathrm{C}$ was just higher at mouth opening (Table 1). A different trend was displayed by the larvae length: larvae incubated at $18^{\circ} \mathrm{C}$ were significantly larger at hatching but according to our experiment similar values at mouth opening were obtained at both treatments (Table 1). The growth of fish expressed either as the specific growth rate (SGR) or as the thermal-unit growth coefficient (TGC) was significantly improved at $18{ }^{\circ} \mathrm{C}$ (Table 1 ). The condition factor apparently was not significantly affected by different temperatures among fish at both hatching and mouth opening (Table 1).
Table 1 Growth performance of Pagellus bogaraveo larvae reared at different temperatures $\left[14^{\circ} \mathrm{C}(\mathrm{T} 14)\right.$ versus $18^{\circ} \mathrm{C}$ (T18)], from hatching $(\mathrm{H})$ to mouth opening (MO)

\begin{tabular}{lcc}
\hline & T14 & T18 \\
\hline Initial body weight (H), mg & $0.25(0.02)$ & $0.25(0.02)$ \\
Final body weight (MO), mg & $0.27(0.02)^{\mathrm{a}}$ & $0.33(0.03)^{\mathrm{b}}$ \\
Initial body length (H), mm & $3.4(0.02)^{\mathrm{a}}$ & $3.9(0.02)^{\mathrm{b}}$ \\
Final body length (MO), mm & $4.9(0.19)$ & $4.9(0.24)$ \\
Initial condition factor (K) & $0.22(0.03)$ & $0.22(0.04)$ \\
Final condition factor (K) & $0.24(0.03)$ & $0.28(0.04)$ \\
Thermal-unit growth coefficient (TGC) & $0.01(0.02)^{\mathrm{a}}$ & $0.05(0.02)^{\mathrm{b}}$ \\
Specific growth rate (SGR) & $0.97(1.03)^{\mathrm{a}}$ & $4.37(1.53)^{\mathrm{b}}$ \\
\hline
\end{tabular}

Within a row, means without a common superscript letter differ significantly $(P<0.05)$. The absence of a superscript indicates no significant difference between treatments. Values are means (standard deviation); $n=6$.

\section{Baseline growth dynamics}

The distinction between white and red muscle was always evident. The larvae $A$ (white muscle) increased from hatching until mouth opening with both temperatures at the post-opercular level and with $14{ }^{\circ} \mathrm{C}$ at the post-anal level $(P<0.05)$ (Table 2$)$. At the postopercular level, the white muscle growth was mainly achieved by hypertrophy (Fig. 1; Table 2). The hyperplastic process gained importance only at the postanal level of the fish, principally of the ones at a higher temperature $(P<0.05)$ (Fig. 1; Table 2). During the trial, the $A$ (red muscle) increased at both temperatures, at the post-anal level $(P<0.05)$, only (Table 2$)$. This enlargement in the red muscle area was related to the $\bar{a}$ (red muscle fibre) and $N$ (red fibres) increase in larvae reared at $18{ }^{\circ} \mathrm{C}(P<0.05)$ and to the total number of fibres increase in larvae reared at $14{ }^{\circ} \mathrm{C}$ $(P<0.05)$ (Table 2).

\section{Temperature effect on white muscle}

No significant temperature-induced effect was observed in A (white muscle) parameter during the experiment (Fig. 2a). Moreover, no significant differences in $A$ (white muscle) were found between the two muscle locations sampled (Table 3).

At mouth opening, the $N$ (white fibres) at the postopercular level (Fig. 2c) was significantly $(P<0.05)$ increased by the highest incubation temperature. At both sampling time points, the $N$ (white fibres) was higher in the post-anal zone of the larvae reared at $14{ }^{\circ} \mathrm{C}(P<0.05)$ (Tables 2 and 3). However, in the larvae reared at $18^{\circ} \mathrm{C}$, these differences seem to be inexistent (Table 3). 
Table 2 Total cross-sectional muscle area [ $A$ (muscle)], total number of fibres [ $N$ (fibres)] and cross-sectional fibre area $[\bar{a}$ (muscle fibre) $]$ of white fibres and red fibres at hatching (H) and mouth opening (MO) in Pagellus bogaraveo

\begin{tabular}{|c|c|c|}
\hline & H & MO \\
\hline \multicolumn{3}{|l|}{ Post-opercular } \\
\hline \multicolumn{3}{|l|}{ T14 } \\
\hline $\begin{array}{l}A \text { (white muscle) } \\
\left(\mu \mathrm{m}^{2}\right)\end{array}$ & $10784.50(0.22)^{\mathrm{a}}$ & $14300.33(0.09)^{\mathrm{b}}$ \\
\hline$N$ (white fibres) & $145.83(0.11)^{\mathrm{a}}$ & $146.17(0.07)^{\mathrm{a}}$ \\
\hline $\begin{array}{l}\bar{a} \text { (white muscle fibre) } \\
\left(\mu \mathrm{m}^{2}\right)\end{array}$ & $73.49(0.15)^{a}$ & $97.82(0.06)^{b}$ \\
\hline$A$ (red muscle) $\left(\mu \mathrm{m}^{2}\right)$ & $377.30(0.15)^{\mathrm{a}}$ & $435.72(0.12)^{\mathrm{a}}$ \\
\hline$N$ (red fibres) & $58.00(0.11)^{a}$ & $61.00(0.11)^{\mathrm{a}}$ \\
\hline $\begin{array}{l}\bar{a} \text { (red muscle fibre) } \\
\left(\mu \mathrm{m}^{2}\right)\end{array}$ & $6.50(0.07)^{\mathrm{a}}$ & $7.20(0.14)^{\mathrm{a}}$ \\
\hline \multicolumn{3}{|l|}{$\mathrm{T} 18$} \\
\hline $\begin{array}{l}A \text { (white muscle) } \\
\left(\mu \mathrm{m}^{2}\right)\end{array}$ & $11707.5(0.11)^{a}$ & $18516.83(0.31)^{\mathrm{b}}$ \\
\hline$N$ (white fibres) & $166.17(0.14)^{\mathrm{a}}$ & $199.00(0.17)^{\mathrm{a}}$ \\
\hline $\begin{array}{l}\bar{a} \text { (white muscle fibre) } \\
\left(\mu \mathrm{m}^{2}\right)\end{array}$ & $71.07(0.13)^{a}$ & $92.69(0.21)^{\mathrm{b}}$ \\
\hline$A$ (red muscle) $\left(\mu \mathrm{m}^{2}\right)$ & $472.71(0.22)^{a}$ & $559.47(0.32)^{\mathrm{a}}$ \\
\hline$N$ (red fibres) & $63.67(0.08)^{a}$ & $71.50(0.21)^{\mathrm{a}}$ \\
\hline $\begin{array}{l}\bar{a} \text { (red muscle fibre) } \\
\left(\mu \mathrm{m}^{2}\right)\end{array}$ & $7.41(0.20)^{\mathrm{a}}$ & $7.67(0.14)^{\mathrm{a}}$ \\
\hline \multicolumn{3}{|l|}{ Post-anal } \\
\hline \multicolumn{3}{|l|}{$\mathrm{T} 14$} \\
\hline $\begin{array}{l}A \text { (white muscle) } \\
\left(\mu \mathrm{m}^{2}\right)\end{array}$ & $10447.33(0.21)^{\mathrm{a}}$ & $15841.17(0.16)^{\mathrm{b}}$ \\
\hline$N$ (white fibres) & $170.67(0.09)^{a}$ & $197.50(0.08)^{\mathrm{b}}$ \\
\hline $\begin{array}{l}\bar{a} \text { (white muscle fibre) } \\
\left(\mu \mathrm{m}^{2}\right)\end{array}$ & $62.11(0.27)^{\mathrm{a}}$ & $80.29(0.15)$ \\
\hline$A$ (red muscle) $\left(\mu \mathrm{m}^{2}\right)$ & $378.63(0.23)^{a}$ & $555.33(0.06)^{\mathrm{b}}$ \\
\hline$N$ (red fibres) & $67.66(0.12)^{\mathrm{a}}$ & $84.50(0.08)^{b}$ \\
\hline $\begin{array}{l}\bar{a} \text { (red muscle fibre) } \\
\left(\mu \mathrm{m}^{2}\right)\end{array}$ & $5.64(0.24)^{a}$ & $6.61(0.11)^{\mathrm{a}}$ \\
\hline \multicolumn{3}{|l|}{$\mathrm{T} 18$} \\
\hline $\begin{array}{l}A \text { (white muscle) } \\
\left(\mu \mathrm{m}^{2}\right)\end{array}$ & $12229.33(0.25)^{\mathrm{a}}$ & $15769.50(0.17)$ \\
\hline$N$ (white fibres) & $172.5(0.13)^{\mathrm{a}}$ & $213.17(0.17)^{\mathrm{b}}$ \\
\hline $\begin{array}{l}\bar{a} \text { (white muscle fibre) } \\
\left(\mu \mathrm{m}^{2}\right)\end{array}$ & $71.22(0.25)^{\mathrm{a}}$ & $75.64(0.23)^{\mathrm{a}}$ \\
\hline$A$ (red muscle) $\left(\mu \mathrm{m}^{2}\right)$ & $360.94(0.18)^{a}$ & $678.16(0.11)^{b}$ \\
\hline$N$ (red fibres) & $81.17(0.05)^{\mathrm{a}}$ & $88.83(0.08)^{\mathrm{b}}$ \\
\hline $\begin{array}{l}\bar{a}(\text { red muscle fibre }) \\
\left(\mu \mathrm{m}^{2}\right)\end{array}$ & $4.46(0.19)^{a}$ & $7.67(0.12)^{b}$ \\
\hline
\end{tabular}

Values are means $(\mathrm{CV}), n=6$. The differences in the morphometric parameters between the two sampling time points (hatching and mouth opening) for each body zone and each temperature are shown; means without a common letter differ significantly $(P<0.05)$.

Throughout the assay, no significant temperature effect was found in the $\bar{a}$ (white muscle fibre) (Fig. 2e). Moreover, at mouth opening, larvae reared at $14{ }^{\circ} \mathrm{C}$ showed a greater $\bar{a}$ (white muscle fibre) at the post-op-
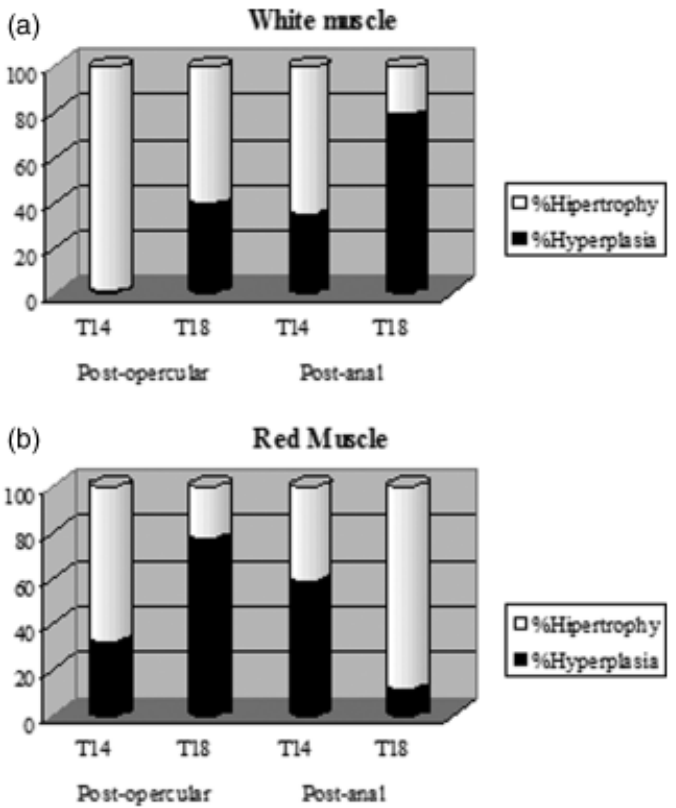

Figure 1 Relative contribution of hyperplasia and hypertrophy to white (a) and red (b) to the total cross-sectional muscle area increase in Pagellus bogaraveo at two different body locations (post-opercular and post-anal), from hatching to mouth opening.

ercular level when compared with the post-anal one $(P<0.05)$ (Tables 2 and 3).

\section{Temperature effect on red muscle}

At mouth opening, the A (red muscle) (Fig. 2b) was increased by the highest incubation temperature $(P<0.05)$. Also at this stage, a higher $A$ (red muscle) in the post-anal level at $14{ }^{\circ} \mathrm{C}$ (Table 2) was the only significant difference observed between the muscle locations $(P<0.05)$ (Table 3$)$.

At hatching, more red fibres were found at the postanal level in the larvae reared at $18^{\circ} \mathrm{C}$ (Fig. 2d) compared with the larvae at a lower temperature $(P<0.05)$, but this difference was apparently inexistent at mouth opening. On comparing muscle locations, the $N$ (red fibres) was superior at the post-anal level at the two sampling time points and at both temperatures $(P<0.05)$ (Tables 2 and 3$)$.

During the vitelline phase, the $4{ }^{\circ} \mathrm{C}$ increase in the water temperature induced a slight but significant increase in the red fibre cross-sectional area $(P<0.05)$ (Fig. 2f). On comparing both muscle locations, at hatching, the $\bar{a}$ (red muscle fibre) was larger at the post-opercular level of the larvae from the $18^{\circ} \mathrm{C}$ group $(P<0.05)$ (Tables 2 and 3$)$. 

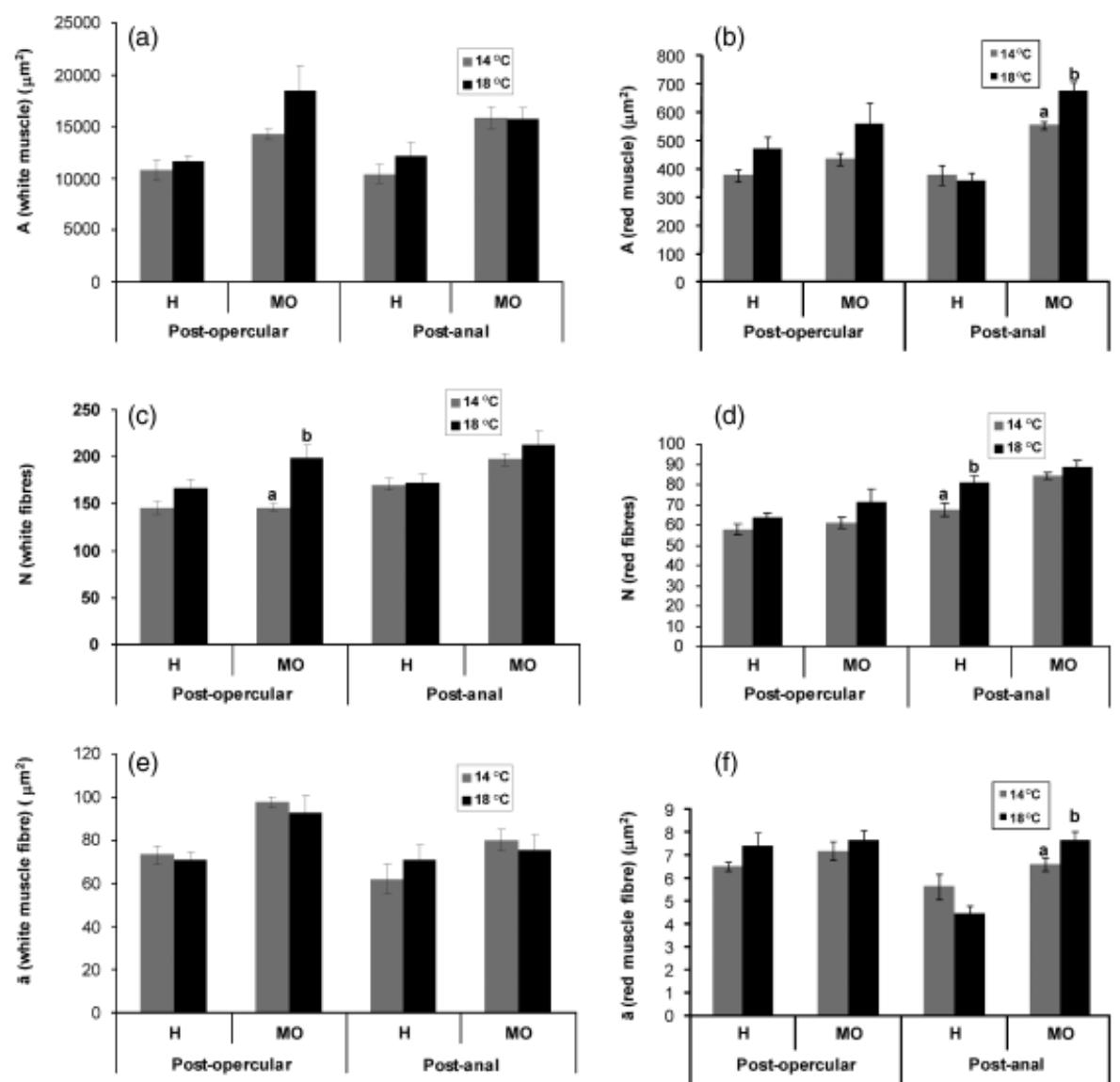

(f)

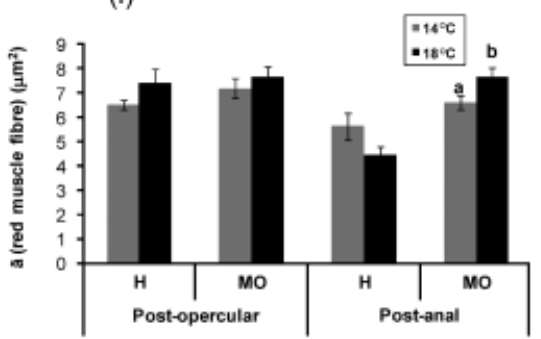

Figure 2 Total cross-sectional muscle area [A (muscle)], total number of fibres [N(fibres)] and cross-sectional fibre area $[\bar{a}$ (muscle fibre)] of white fibres (a, c, e) and red fibres (b, d, f) at hatching (H) and mouth opening (MO) in Pagellus bogaraveo. Values are means $\pm \mathrm{SE}, n=6$. The effect of the incubating temperatures on the morphometric parameters estimated is shown; means without a common letter differ significantly $(P<0.05)$. The absence of letters indicates no significant difference between treatments.

\section{Discussion}

One key factor in the commercial production of marine fish species is the control of hatchery production procedures (broodstock and egg managements, larval rearing and feeding). Blackspot seabream studies on larvae culture techniques began in the 1990s (Peleteiro, Olmedo, Gómez \& Alvarez-Blázquez 1997; Olmedo et al. 1998; Micale, Maricchiolo \& Genovese 2002), but this is the first study on the influence of two water temperatures $\left(14\right.$ and $\left.18^{\circ} \mathrm{C}\right)$ on the larvae growth and on muscle cellularity from hatching to mouth opening. It was also the first study in fish aimed at establishing whether the temperature influence is similar anteriorly and posteriorly in the body. The use of replicates for each treatment was not possible in this study, however, we decided to conduct the experiment because the baseline effects of tem- perature on the muscle growth were anticipated by very good background information and only a preliminary estimate of this effect was required. Moreover, all the husbandry conditions and water parameters were accurately controlled so that the temperature was the only parameter that could vary in the two experimental groups. All available data revealed that this was the case. Thus, our design allowed a reliable general overview of the effect of temperature on the blackspot seabream larvae muscle growth.

As hypothesized, the development rate of the embryos was improved by an increase in the rearing temperature within the tolerance range of the blackspot seabream, as reported for other species (Usher et al. 1994; Nathanailides et al. 1995; Johnston, Cole, Abercromby \& Vieira 1998; Ayala, López-Albors, Gil, GarcíaAlcázar, Abellán, Alarcón, Alvarez, Ramirez-Zarzosa \& 
Table 3 Significance of differences between Pagellus bogaraveo muscle location (post-opercular versus post-anal) for the estimated morphometric parameters at different temperatures $\left[14{ }^{\circ} \mathrm{C}(\mathrm{T} 14)\right.$ versus $\left.18{ }^{\circ} \mathrm{C}(\mathrm{T} 18)\right]$, evaluated using the Student' $t$-test for dependent samples

\begin{tabular}{|c|c|c|c|c|}
\hline & \multicolumn{2}{|l|}{ T14 } & \multicolumn{2}{|l|}{ T18 } \\
\hline & $\mathbf{H}$ & MO & $\mathbf{H}$ & MO \\
\hline \multicolumn{5}{|c|}{ Post-opercular versus post-anal levels } \\
\hline \multicolumn{5}{|c|}{ White muscle } \\
\hline$A$ & NS & NS & NS & NS \\
\hline$N$ & $P<0.01$ & $P<0.001$ & NS & NS \\
\hline $\bar{a}$ & NS & $P<0.001$ & NS & NS \\
\hline \multicolumn{5}{|c|}{ Red muscle } \\
\hline A & NS & $P<0.001$ & NS & NS \\
\hline$N$ & $P<0.001$ & $P<0.05$ & $P<0.01$ & $P<0.05$ \\
\hline $\bar{a}$ & NS & NS & $P<0.01$ & NS \\
\hline
\end{tabular}

$\mathrm{H}$, hatching; MO, mouth opening; $A$, muscle area; $N$, total number of fibres; $\bar{a}$, cross-sectional fibre area; NS, non-significant

Moreno 2001). Our data suggest that the yolk depletion speed in blackspot seabream depends on the water temperature. This could mean that, at high temperatures, this species may be better able to resist starvation and may be reared with high survival and rapid growth. Comparison of blackspot seabream larvae at equivalent development stages confirmed that growth differences were induced by temperature. At hatching, larvae incubated at a higher temperature were already longer. The same was observed in the sea bass, where the body length was greater in larvae incubated at higher temperatures (López-Albors et al. 2003; Alami-Durante, Rouel \& Kentouri 2006). Larval length at hatch is an important parameter influencing the initial locomotion performance, such as swimming speed, escape response and predator avoidance (Blaxter 1992). Further temperature influences in the pre-larval period were not related to body length but rather to weight, as $18^{\circ} \mathrm{C}$ larvae reached the stage of mouth opening with a higher body weight than $14^{\circ} \mathrm{C}$ larvae. Our explanatory hypothesis is that during the pre-larval phase, the use of vitelline energy to satisfy the requirements related to organogenesis causing acceleration in vitelline sac reabsorption was favoured by the higher temperature (Johnston 1993).

In general, the $A$ (white muscle) increased until mouth opening at both locations. The $A$ (red muscle), however, increased with age only at the post-anal region. These results differ from those included in a previous study with this fish species (Silva, Valente, Olmedo, Galante, Monteiro \& Rocha 2009), covering hatching to juvenile, where a pause in muscle growth of both fibre types was observed at mouth opening.
As to the increase observed at the post-opercular level, the difference in muscular growth observed could be explained by the fact that the larvae displayed different growth dynamics in the two studies. Accordingly, in the previous one (Silva et al. 2009) larvae grew mainly in length $(3.6-6.0 \mathrm{~mm})$, reaching mouth opening faster, whereas in the current one, the larvae growth at mouth opening was mainly related to a weight increase. The present results show that the white muscle hypertrophy was the main contributor to the $A$ (white muscle) growth at the post-opercular body position, which relates well with the above-mentioned weight increase. As to the postanal level, the increase observed in the present work in both $A$ (white muscle) and $A$ (red muscle) was due to both hyperplastic and hypertrophic mechanisms. Also, at the post-anal level, the current results were different from those observed in the previous study (Silva et al. 2009). This is probably related to the different position of the post-anal level resulting from the larvae length, because as noted in this and in the previous study (Silva et al. 2009), and for the first time in this species, differences exist in the cellularity between different body zones. Previous research showed species differences in muscle growth in the first days after hatching. An uninterrupted myogenesis in fast muscle after hatching, for example, was also apparent in some teleost species including salmon (Stickland, White, Mescall, Crook \& Thorpe 1988), rainbow trout (Oncorhynchus mykiss, Walbaum) (Stoiber \& Sänger 1996; Xie, Mason, Wilkes, Goldspink, Fauconnueau \& Stickland 2001), zebrafish (Danio rerio, Hamilton) (Barresi, D’Angelo, Hernandez \& Devoto 2001) and pearlfish (Rutilus meidingeri, Heckel) (Steinbacher, Haslett, Six, Gollmann, Sänger \& Stoiber 2006). A pause in the recruitment of new fibres in the first days after hatching was, however, observed in herring (Johnston 1993), turbot (Gibson \& Johnston 1995; Johnston et al. 1998), cod (Galloway, Korsvik \& Kryvi 1999) and sole (Veggetti, Rowlerson, Radaelli, Arrighi \& Domeneghini 1999). Besides these inter-specific differences in fish muscle growth in the first days after hatching, our study showed that the influence of temperature in muscle cellularity is somewhat variable even for the same species. This intra-specific variability is probably related to genetic variation and/or differences in the spawning condition of the parents.

The embryonic growth of blackspot seabream axial musculature was significantly affected by temperature. Fish incubated at higher temperatures $\left(18^{\circ} \mathrm{C}\right)$ at hatching showed a higher number of red fibres at the post-anal level than those incubated at 
lower temperatures $\left(14^{\circ} \mathrm{C}\right)$. The presence of more red fibres in the post-anal part of the newly hatched larvae suggested that, towards the end of embryonic life, more red fibres were formed in the caudal myotomes. Also, Rowlerson et al. (1995) suggested that during larval life in sea bream, the hyperplastic growth of slow muscle fibres occurred in a very restricted zone of the post-anal muscle. It is suggested by our data that this process is not restricted to a species and is modulated by temperature. The majority of the works studied the influence of incubation temperature in white muscle only, and large inter-specific differences in embryonic fish muscle growth in response to changes in water temperature are found. The present results in white muscle are in agreement with those obtained in cyprinids, where higher pre-hatch temperatures were found to have no significant effect on the fibre number and fibre size in common carp ( $\mathrm{Cy}$ prinus carpio Linnaeus) at hatching (Alami-Durante, Bergot, Rouel \& Goldspink 2000). However, this scenario is not universal in fish and seems to depend on the species. Thus, in Atlantic salmon (Stickland et al. 1988; Usher et al. 1994; Nathanailides et al. 1995), common whitefish (Coregonus lavaretus, Linnaeus) (Hanel, Karjalainen \& Wiser 1996) and Arctic cod (Gadus morhua, Linnaeus) (Galloway, Korsvik \& Kryvi 1998), a higher pre-hatch temperature was not responsible for modifying white muscle area but decreases in the fibre number and increases in the fibre size at hatching or 1 day later were reported. In turbot (Scophthalmus maximus, Linnaeus) (Gibson \& Johnston 1995) and in sea bass (Alami-Durante et al. 2006), it was observed that incubation at higher temperatures increased white muscle size and white fibre size at hatching, but the number of white fibres was not altered. In Atlantic halibut (Hippoglossus hippoglossus, Linnaeus), white muscle size, fibre number and fibre size at hatching were reduced by higher incubation temperatures (Galloway et al. 1999). Our results further stress the complex nature of muscle growth and development in fish, and highlight the species-specific response of myogenesis to changes in incubation temperature.

At mouth opening, the total number of white fibres was greater at the post-opercular level of larvae reared at $18{ }^{\circ} \mathrm{C}$. The present results are in accordance with those from herring, where fibre hyperplasia in the anterior part of the larvae was augmented due to warmer temperatures (Vieira \& Johnston 1992; Johnston et al. 1995). At the end of the endogenous feeding period, the total red muscle area at the post-anal level was larger in larvae at $18{ }^{\circ} \mathrm{C}$. This significant outcome re- sulted from the $\bar{a}$ (red muscle fibre), because a statistically significant temperature effect on this parameter was observed when the fish length was considered to be a covariate. Recent studies found that early temperature produced early effects on somatic both growth and muscle fibre phenotype that persisted until adult life (López-Albors, Abdel, Periago, Ayala, Alcázar, Graciá, Nathanailides \& Vázquez 2008; Macqueen, Robb, Olsen, Melstveit, Paxton \& Johnston 2008). We believe that the temperature regime before first feeding affected the number of undifferentiated myoblasts and hence the future growth potential. If so, then it might be possible to manipulate temperature during embryonic development, to optimize the final muscle fibre number and induce growth rate improvements.

Comparing the results obtained in both body locations in our experiment, the total number of white fibres was always higher at the post-anal level in the larvae from the $14{ }^{\circ} \mathrm{C}$ group. Simultaneously, at first feeding, the white fibres tended to have a smaller mean cross-sectional area at the post-anal level. Also, at both sampling time points, and for both temperatures, the total number of red fibres was larger at the post-anal level, supporting what was stated above about the post-anal zone being most likely the main location for the red fibre hyperplasia during larval growth. Our experiment emphasizes the importance of looking at different body locations when studying fish muscle growth. If we had investigated only the post-anal zone, an incorrect conclusion would have been made, i.e., that temperature had no effect on the white muscle fibre number.

In conclusion, this study showed that the development rate of blackspot seabream was accelerated by a higher temperature $\left(18^{\circ} \mathrm{C}\right)$. Also, the larval muscle growth dynamics was affected by the temperature via the production of new white muscle fibres (hyperplasia) at the post-opercular level and on the size of the red fibre and, consequently, on the size of the total red muscle area at the post-anal level. It was also demonstrated that the axial musculature of larvae displayed a non-similar response to the different early temperatures between the post-anal and the postopercular levels. Further investigation is required to determine whether these different responses are particular for that species or body size.

\section{Acknowledgments}

This work was partially supported by FCT PhD Grant SFRH-BD-14068-2003 awarded to P. Silva and FCT 
pluriannual funding awarded to CIIMAR-CIMAR LA. The authors are greatly indebted to the 'Instituto Español de Oceanografía' (Centro Oceanográfico de Vigo, España), which provided the fish. Handling and care of animals were conducted according to the EU guiding principles for animal research $(86 / 609 / \mathrm{EU})$ and the Portuguese law (Decreto Lei No. 192/92 and 197/96, regulated by Portaria No. 1005/92, No.466/95 and No. 1131/97). The experiment was part of a project approved by the Portuguese Foundation for Science and Technology and also approved by the Scientific Council of the ICBAS - Univ. Porto (which is advised by an official Ethics Committee).

\section{References}

Alami-Durante H., Bergot P., Rouel M. \& Goldspink G. (2000) Effects of environmental temperature on the development of the myotomal white muscle in larval carp (Cyprinus carpio L.). Journal of Experimental Biology 203, 3675-3688.

Alami-Durante H., Rouel M. \& Kentouri M. (2006) New insights into temperature-induced white muscle growth plasticity during Dicentrarchus labrax life: a developmental and allometric study. Marine Biology 149, 1551-1565.

Ayala M.D., López-Albors O., Gil F., Latorre R., Vásquez J.M., García-Alcázar A., Abellán E., Ramírez G. \& Moreno F. (2000) Temperature effect on muscle growth of the axial musculature of the sea bass (Dicentrarchus labrax L.). Anatomia, Histologia, Embryologia: Journal of Veterinary Medicine Series C 29, 235-241.

Ayala M.D., López-Albors O., Gil F., García-Alcázar A., Abellán E., Alarcón J.A., Alvarez M.C., Ramirez-Zarzosa G. \& Moreno F. (2001) Temperature effects on muscle growth in two populations (Atlantic and Mediterranean) of sea bass, Dicentrarchus labrax L. Aquaculture 202, 359-370.

Barresi M.J., D’Angelo J.A., Hernandez L.P. \& Devoto S.H. (2001) Distinct mechanisms regulate slow-muscle development. Current Biology 11, 1432-1438.

Bauchot M.-L. \& Hureau J.C. (1990) Sparidae. In: Check-List of the Fishes of the Eastern Tropical Atlantic (CLOFETA), Vol. 2 (ed. by J.C. Quero, J.C. Hureau, C. Karrer, A. Post \& L. Saldanha), pp. 790-812. JNICT, Lisbon, Portugal; SEI, Paris \& UNESCO, Paris.

Blaxter J.H.S. (1992) The effect of temperature on larval fishes. The Netherlands Journal of Zoology 42, 336-357.

Galloway T.F., Korsvik E. \& Kryvi T.F. (1998) Effect of temperature on viability and axial muscle development in embryos and yolk sac larvae of the Northeast Arctic cod (Gadus mohua). Marine Biology 132, 559-567.

Galloway T.F., Korsvik E. \& Kryvi T.F. (1999) Muscle growth and development in Atlantic cod larvae (Gadus morhua L.) related to different somatic growth rates. Journal of Experimental Biology 202, 2111-2120.
Gibson S. \& Johnston I.A. (1995) Temperature and development in larvae of the turbot Scophthalmus maximus (L.). Marine Biology 124, 17-25.

Hanel R., Karjalainen J. \& WiserW. (1996) Growth of swimming muscles and its metabolic cost in larvae of whitefish at different temperatures. Journal of Fish Biology 48, 937-951.

Johnston I.A. (1993) Temperature influences muscle differentiation and the relative timing of organogenesis in herring (Clupea harengus) larvae. Marine Biology 116, 363-379.

Johnston I.A. (2001) Genetic and environmental determinants of muscle growth patterns. In: Muscle Development and Growth. Fish Physiology Series, Vol. 18 (ed. by I.A. Johnston), pp. 141-186. Academic Press, San Diego, CA, USA.

Johnston I.A., Vieira V.L.A. \& Abercromby M. (1995) Temperature and myogenesis embryos of the Atlantic herring (Clupea harengus). Journal of Experimental Biology 198, 1389-1403.

Johnston I.A., Cole N.J., Abercromby M. \& Vieira V.L.A. (1998) Embryonic temperature modulates muscle growth characteristics in larval and juvenile herring. Journal of $E x$ perimental Biology 201, 623-646.

Krug H.M. (1990) The Azorean Blackspot seabream, Pagellus bogaraveo (Brunnich, 1768) (TELEOSTEI, SPARIDAE). Reproduction cycle, hermaphrodism, maturity and fecundity. Cybium 14, 151-159.

Larsen J.O., Gundersen H.J.G. \& Nielsen J. (1998) Global spatial sampling with isotropic virtual planes: estimators of length density and total length in thick, arbitrarily orientated sections. Journal of Microscopy 19, 238-248.

López-Albors O., Ayala M.D., Gil F., García-Alcázar A., Abellán E., Latorre R., Ramírez-Zarzosa G. \& Vázquez J.M. (2003) Early temperature effects on muscle growth dynamics and histochemical profile of muscle fibres of sea bass Dicentrachus labrax L., during larval and juvenile stages. Aquaculture 220, 385-406.

López-Albors O., Abdel I., Periago M.J., Ayala M.D., Alcázar A.G., Graciá C.M., Nathanailides C. \& VázquezJ.Ma. (2008) Temperature influence on the white muscle growth dynamics of the sea bass Dicentrarchus labrax, L. Flesh quality implications at commercial size. Aquaculture 277, 39-51.

Macqueen D.J., Robb D.H.F., Olsen T., Melstveit L., Paxton C.G.M. \& Johnston I.A. (2008) Temperature until the 'eyed stage' of embryogenesis programmes the growth trajectory and muscle phenotype of adult Atlantic salmon. Biology Letters 4, 294-298.

Micale V., Maricchiolo G. \& Genovese L. (2002) The reproductive biology of blackspot sea bream Pagellus bogaraveo in captivity. I. gonadal development, maturation and hermaphroditism. Journal of Applied Ichthyology 18, 172-176.

Nathanailides C., López-Albors O. \& Stickland N.C. (1995) Influence of prehatch temperature on the development of muscle cellularity in posthatch Atlantic salmon (Salmo salar). Canadian Journal of Fish Aquaculture Science $\mathbf{5 2}$, 675-680. 
Olmedo M., Peleteiro J.B., Alvarez-Blázquez B. \& Gómez C. (1998) First experiences with larval culture of blackspot seabream (Pagellus bogaraveo). ICES Annual Conference, September 16-19, 1998, Lisboa, Portugal. ICES CM 1998/L21.

Peleteiro J.B., Olmedo M., Gómez C. \& Alvarez-Blázquez B. (1997) Study of reproduction in captivity of blackspot seabream (Pagellus bogaraveo, B.). Embryonic development and consumption of vitelline sac. ICES CM 1997/HH19.

Rowlerson A., Mascarello F., Radaelli G. \& Veggetti A. (1995) Differentiation and growth of muscle in the fish Sparus aurata (L): II. Hyperplastic and hypertrophic growth of lateral muscle from hatching to adult. Journal of Muscle Research and Cell Motility 16, 223-236.

Sánchez F. (1983) Biology and fishery of the red sea bream (Pagellus bogaraveo B.) in VI, VII and VIII subareas of ICES. C.M. $1983 / \mathrm{G}: 38$.

Savnik A., Bliddal H., Nyengaard J.R. \& Thomsen H.S. (2002) MRI of the arthritic finger joints: synovial membrane volume determination, a manual vs a stereologic method. European Radiology 12, 94-98.

Silva P., Valente L.M.P., Olmedo M., Galante M.H., Monteiro R.A.F. \& Rocha E. (2009) Hyperplastic and hypertrophic growth of lateral muscle in the fish blackspot seabream, Pagellus bogaraveo, from hatching to juvenile. Journal of Fish Biology 74, 37-53.

Steinbacher P., Haslett J.R., Six M., Gollmann H.P., Sänger A.M. \& Stoiber W. (2006) Phases of myogenic cell activation and possible role of dermomyotome cells in teleost muscle formation. Development Dynamics 235 , 3132-3143.
Stickland N.C., White R.N., Mescall P.E., Crook A.R. \& Thorpe J.E. (1988) The effect of temperature on myogenesis in embryonic development of the Atlantic salmon (Salmo salar L.). Anatomy and Embryology 178, 253-257.

Stoiber W. \& Sänger A.M. (1996) An electron microscopic investigation into possible source of new muscle fibres in teleost fish. Anatomy and Embryology 194, 569-579.

Usher M.L., Stickland N.C. \& Thorpe J.E. (1994) Muscle development in Atlantic salmon (Salmo salar) embryos and the effect on muscle cellularity. Journal of Fish Biology $\mathbf{4 4}$, 953-964.

Valente L.M.P., Rocha E., Gomes E.F.S., Silva M.W., Oliveira M.H., Monteiro R.A.F. \& Fauconneau B. (1999) Growth dynamics of white and red muscle fibres in fast and slow growing strains of rainbow trout. Journal of Fish Biology 55, 675-691.

Veggetti A., Rowlerson A., Radaelli G., Arrighi S. \& Domeneghini C. (1999) Post-hatching development of the gut and lateral muscle in the sole. Journal of Fish Biology $\mathbf{5 5}$ (Suppl. A), 44-65.

Vieira V.L.A. \& Johnston I.A. (1992) Influence of temperature on muscle fibre development in larvae of the herring (Clupea harengus L). Marine Biology 112, 333-341.

Xie S.Q., Mason P.S., Wilkes D., Goldspink G., Fauconnueau B. \& Stickland N.C. (2001) Lower environmental temperature delays and prolongues myogenic regulatory factor expression and muscle differentiation in rainbow trout (Oncorhynchus mykiss) embryos. Differentiation 68, 106-114.

Zar J.H. (1996) Biostatistical Analysis. Prentice-Hall International, London, UK. 